\title{
A phase II study of paclitaxel and capecitabine as a first-line combination chemotherapy for advanced gastric cancer
}

\author{
HJ Kang', HM Chang', TW Kim', M-H Ryu', H-J Sohn', JH Yook², ST Oh², BS Kim², J-S Lee' and Y-K Kang", \\ 'Division of Oncology, Department of Medicine, University of Ulsan College of Medicine, Asan Medical Center, Seoul, Korea; ${ }^{2}$ Department of Surgery, \\ University of Ulsan College of Medicine, Asan Medical Center, Seoul, Korea
}

\begin{abstract}
Paclitaxel and capecitabine, which have distinct mechanisms of action and toxicity profiles, have each shown high activity as single agents in gastric cancer. Synergistic interaction between these two drugs was suggested by taxane-induced upregulation of thymidine phosphorylase. We, therefore, evaluated the antitumour activity and toxicities of paclitaxel and capecitabine as first-line therapy in patients with advanced gastric cancer (AGC). Patients with histologically confirmed unresectable or metastatic AGC were treated with capecitabine $825 \mathrm{mg} \mathrm{m}^{-2}$ p.o. twice daily on days I- 14 and paclitaxel $175 \mathrm{mg} \mathrm{m}^{-2}$ i.v. on day I every 3 weeks until disease progression or unacceptable toxicities. Between June 2002 and May 2004, 45 patients, of median age 57 years (range = 38-73 years), were treated with the combination of capecitabine and paclitaxel. After a median 6 cycles (range $=1-9$ cycles) of chemotherapy, 43 were evaluable for toxicity and response. A total of 2 patients showed complete response and 20 showed partial response making the overall response rate $48.9 \%(95 \% \mathrm{Cl}=30.3-63.5 \%)$. After a median follow-up of 42.2 months (range $=31.2-$ 54.3 months), median time to progression was 5.6 months $(95 \% \mathrm{Cl}=3.9-7.2$ months) and median overall survival was II.3 months ( $95 \% \mathrm{Cl}=8.1-\mid 4.4$ months). Grade 3 or 4 adverse events include neutropaenia (46.5\% of patients), hand-foot syndrome (9.3\%), arthralgia (9.3\%), and asthenia (4.7\%). There was no neutropaenic fever or treatment-related deaths. Paclitaxel and capecitabine combination chemotherapy was active and highly tolerable as a first-line therapy for AGC.
\end{abstract}

British Journal of Cancer (2008) 98, 316-322. doi:I0.1038/sj.bjc.6604I86 www.bjcancer.com

Published online 22 January 2008

(c) 2008 Cancer Research UK

Keywords: paclitaxel; capecitabine; advanced gastric cancer

Although the overall incidence of gastric cancer has steadily declined in many Western countries during the last few decades (Jemal et al, 2002), it is still the most common tumour in Korea (Bae et al, 2002). Gastric cancer is often diagnosed at a very advanced stage, with approximately half of all patients presenting with unresectable, locally advanced, or metastatic disease. For patients with advanced gastric cancer (AGC), the median survival is only 6-10 months, and 5-year survival rates are $<10 \%$.

Four randomised studies comparing best-supportive care with best-supportive care plus chemotherapy for AGC have shown that chemotherapy can improve survival and quality of life (Murad et al, 1993; Pyrhonen et al, 1995; Schipper and Wagener, 1996; Glimelius et al, 1997). The combination of 5-FU plus cisplatin (FP) resulted in improved response rates compared with 5-FU, doxorubicin and mitomycin (FAM) or 5-FU single-agent therapy (Kim et al, 1993), and showed a trend towards improved response rates when compared with 5-FU, doxorubicin and methotrexate (FAMTX) or etoposide, leucovorin and bolus 5-FU (ELF) (Vanhoefer et al, 2000). The combination of epirubicin, cisplatin, and infusional 5-FU (ECF) led to longer survival than the

*Correspondence: Dr Y-K Kang, Division of Oncology, Department of Medicine, Asan Medical Center, 388-I Pungnap-dong, Songpa-gu, Seoul, South Korea 138-736; E-mail: ykkang@amc.seoul.kr

Received 26 June 2007; revised 12 November 2007; accepted 12 December 2007; published online 22 January 2008 combination of 5-FU, doxorubicin, and high-dose methotrexate (FAMTX) (median overall survival (OS) 8.9 months $v s 5.8$ months) (Webb et al, 1997). Thereafter, these two FP-based chemotherapy regimens (FP and $\mathrm{ECF}$ ) became a standard reference regimen in first-line treatment for AGC. Nonetheless, the treatment outcomes with these regimens were not satisfactory either in efficacy or safety, such as inconvenience and complication associated with portable pump for administration of infusional 5-FU, and nausea/ vomiting and neurotoxicity related with cisplatin. So, development of more effective or better tolerable chemotherapy regimens have been an urgent task in AGC.

Paclitaxel (Taxol ${ }^{\mathbb{R}}$; Bristol-Meyers Squibb Company, Princeton, NJ, USA), the prototype taxane compound that interferes with tubulin assembly (Rowinsky et al, 1990), has been studied extensively in patients with previously treated or untreated gastric cancer. As a single agent, paclitaxel induced responses in $11-17 \%$ of previously untreated patients (Ajani et al, 1998; Garcia et al, 2001), and activity was also seen in previously treated patients (Cascinu et al, 1998; Yamada et al, 2001). The in vitro cytotoxic effects of paclitaxel plus 5-FU were found to depend on the schedule used, in that application of paclitaxel before 5-FU enhanced cytotoxicity, whereas the application of paclitaxel after 5 -FU resulted in a less than additive cytotoxic effect (Kano et al, 1996). In patients with AGC, the combination of these two drugs had response rates between 13 and $65.5 \%$, with a rather lowtoxicity profile (Cascinu et al, 1997; Murad et al, 1999). 
Capecitabine (N4-pentoxycarbonyl-5'-deoxy-5-fluorocytidine; Xeloda ${ }^{\mathbb{R}}$; Hoffmann-La Roche Ltd, Basel, Switzerland) is a 5-FU prodrug developed to reduce the toxicity and enhance the intratumour concentrations of 5-FU. Capecitabine is absorbed as an intact molecule from the small bowel mucosa and converted sequentially to 5-FU in a multistep enzymatic process (Bollag and Hartmann, 1980; Hartmann and Bollag, 1980). In the first step, capecitabine is metabolised by hepatic carboxyl esterase to $5^{\prime}$ deoxy-5-fluorocytidine ( $5^{\prime}$-DFCR). This intermediate is metabolised by cytidine deaminase to doxifluridine ( $5^{\prime}$-DFUR) in hepatic and extrahepatic tissues, including malignant tumours. Finally, $5^{\prime}$ DFUR is converted to 5-FU by the pyrimidine nucleoside phosphorylase thymidine phosphorylase (dThdPase), a potent tumour-associated angiogenesis factor preferentially expressed in malignant cells (Ishikawa et al, 1998a). In preclinical xenograft models, capecitabine was highly active against several tumours, including breast, colorectal, gastric, and cervical tumours (Ishikawa et al, 1998b; Ishitsuka, 2000), and against both 5-FU-sensitive and 5-FU-resistant tumours (Cao et al, 1997). Intermittent capecitabine $\left(1250 \mathrm{mg} \mathrm{m}^{-2}\right.$ daily dose for 14 days, followed by a 7 -day rest period) was shown to be active as a single agent in previously untreated AGC patients, with a response rate of $28.2 \%$ in 39 patients (Hong et al, 2004). Moreover, the combination of capecitabine with other drugs, such as cisplatin, oxaliplatin, epirubicin, and docetaxel, had an objective response rate of $40-$ $68 \%$ as first-line treatment in patients with AGC (Kim et al, 2002; Kang et al, 2004; Park et al, 2004, 2006; Cho et al, 2005).

In human colon cancer xenograft model, thymidine phosphorylase is upregulated and synergy between paclitaxel and capecitabine has been observed (Sawada et al, 1998). The activity of capecitabine in patients with breast cancer refractory to paclitaxel and anthracyclines suggests that the combination of capecitabine and paclitaxel may be effective in treating patients with advanced breast cancer (Blum et al, 1999). Doses recommended are capecitabine $1650 \mathrm{mg} \mathrm{m}^{-2}$ per day orally for 14 days and paclitaxel $175 \mathrm{mg} \mathrm{m}^{-2}$ i.v. every 3 weeks (Villalona-Calero et al, 2001).

We, therefore, performed a phase II study to evaluate the antitumour activity and toxicities of the combination of paclitaxel and capecitabine as first-line therapy in patients with AGC.

\section{PATIENTS AND METHODS}

\section{Patient selection}

Patients with histologically confirmed AGC, with at least one measurable lesion of longest diameter $\geqslant 2 \mathrm{~cm}$, were considered eligible for this study. In addition, patients 18-75 years old with ECOG performance status of $0-2$ and adequate liver, renal, and bone marrow functions were eligible. Prior chemotherapy for advanced disease was not permitted, but adjuvant chemotherapy was allowed, providing it was completed at least 6 months before the start of study treatment. Patients were excluded if they had been previously exposed to taxane although fluoropyrimidine was allowed as adjuvant therapy. Patients with unresolved bowel obstruction or malabsorption syndrome were excluded. The protocol was approved by the Institutional Review Board of the Asan Medical Center, and all patients provided written informed consent before enrollment.

\section{Treatment schedule}

Treatment consisted of i.v. paclitaxel $175 \mathrm{mg} \mathrm{m}^{-2}$ (diluted in $500 \mathrm{ml}$ of $0.9 \%$ sodium chloride solution) for $3 \mathrm{~h}$ on day 1 , followed by oral capecitabine $825 \mathrm{mg} \mathrm{m}^{-2}$ twice daily from the evening of day 1 to the morning of day 15, followed by a 7-day treatment-free interval, in each 3-week cycle (Villalona-Calero et al, 2001). Patients received standard i.v. hypersensitivity prophylaxis, including dexamethasone $20 \mathrm{mg}$, diphenhydramine $50 \mathrm{mg}$, and ranitidine $50 \mathrm{mg}, 30 \mathrm{~min}$ before administration of paclitaxel.

Patients with response or stable disease received a maximum of 9 cycles of chemotherapy, or until disease progression, unacceptable toxicity, or refusal by the patient. Patients withdrawing from the study due to adverse effects of study drugs could continue on monotherapy.

\section{Dose modification for adverse events}

Toxicity was evaluated before each treatment cycle according to the National Cancer Institute Common Toxicity Criteria (NCI CTC), version 2.0. To begin the next treatment cycle, each patient was required to have a platelet count $\geqslant 100 \times 10^{9} 1^{-1}$, an absolute neutrophil count $\geqslant 1.5 \times 10^{9} 1^{-1}$ and resolution or improvement of clinically significant non-haematological adverse events, except alopecia, to grade 1 or 0 . A treatment delay of up to 1 week was permitted without dose reduction.

Treatment was continued at the same dose, without interruption or dose reduction, in patients experiencing grade 1 or other toxicities considered unlikely to become serious or life threatening (e.g., alopecia). For all other treatment-related adverse events of grade 2 or higher (except grade 3 peripheral neuropathy or neutropaenia, as described below), a dose modification scheme was implemented. Dose reduction was not required following the first appearance of any grade 2 toxicity, although treatment was interrupted/delayed until the toxicity had resolved to grades $0-1$ and symptomatic treatment was initiated when possible. Treatment with both agents was interrupted/delayed and the dose of both agents was reduced by $25 \%$ in patients who experienced a second occurrence of any grade 2 toxicity or at the first occurrence of a grade 3 toxicity. If patients experienced a third occurrence of any grade 2 toxicity or a second occurrence of any grade 3 toxicity, treatment was interrupted/delayed until the toxicity resolved to grades $0-1$ and the dose of both agents was reduced by $50 \%$. Treatment with both agents was discontinued if, despite dose reduction, any grade 2 toxicity occurred for a fourth time or any grade 3 toxicity for a third time. Treatment was also discontinued if patients experienced a grade 4 non-haematological toxicity.

Paclitaxel was discontinued and capecitabine treatment was modified according to the scheme outlined above in patients experiencing grade 3 peripheral neuropathy. Paclitaxel dose was permanently reduced by $25 \%$ for patients who developed grade 4 neutropaenia for more than 5 days, or grade 3 or 4 neutropaenia associated with a temperature of $\geqslant 38^{\circ} \mathrm{C}$. Paclitaxel was discontinued if patients receiving the reduced dose experienced grade 4 or febrile neutropaenia. Patients with grade 4 thrombocytopaenia were retreated with a $25 \%$ dose reduction after recovery. As capecitabine was not expected to worsen or prolong neutropaenic episodes, treatment with this agent could be continued during episodes of grade 3-4 neutropaenia. However, capecitabine was interrupted if any other grade 2 toxicity developed during the neutropaenic episodes.

\section{Assessment of compliance and dose intensity}

Compliance to capecitabine treatment was monitored by questioning patients and counting their remaining pills at each outpatient visit. The ratio of the actual administered dose to the scheduled dose was calculated. Dose intensity was defined as the total amount of drug given $\left(\mathrm{mg} \mathrm{m}^{-2}\right)$ divided by the number of weeks.

\section{Pretreatment, follow-up studies and response evaluation}

Prestudy screening assessments, completed within the 3 weeks preceding treatment, included a full medical history, vital signs and physical measurements, haematological and blood chemistry 
tests, electrocardiogram, chest X-ray, and computed tomography (CT) scans.

Complete blood counts with differential counts were performed every week to assess haematological toxicities, and physical examinations and biochemical tests were performed before each chemotherapy cycle. Response evaluation was performed by CT scan every 2 cycles until disease progression or withdrawal from study medication. Tumour response was classified on the basis of the response evaluation criteria in solid tumours guidelines (Therasse et al, 2000), with responses confirmed as lasting longer than 4 weeks.

\section{Statistical analysis}

All enrolled patients were included in the intention-to-treat (ITT) analysis of efficacy. This trial was designed using Simon's twostage phase II designs (Simon, 1987). Assuming a target level of interest, $p_{1}=0.5$, and a lower activity level, $p_{0}=0.3$, we planned to enroll 19 patients initially. If seven or more responses were observed, the trial would be continued. Accrual would be planned to a total of 44 patients assuming a $10 \%$ dropout rate due to protocol non-compliance. This design provides a probability $\leqslant 0.05$ of accepting drugs worse than $p_{0}$ and a probability $\leqslant 0.20$ of rejecting drugs better than $p_{1}$.

Time to progression (TTP), survival and duration of response were estimated as secondary end points by the Kaplan-Meier method. The duration of response was defined as the interval from the onset of complete response (CR) or partial response (PR) until first appearance of evidence of progression. Time to progression was calculated from the date of entry into the study until the date of progression, and OS was measured from the date of entry to the date of last follow-up or death.

\section{RESULTS}

\section{Patient characteristics}

A total of 45 patients were enrolled from June 2002 to May 2004, and their baseline characteristics are shown in Table 1. Their median age was 57 years, and 42 of 45 patients (93.3\%) had a good performance status (ECOG 0 or 1). Ten patients had recurrent disease after previous curative gastrectomy and nine had previous adjuvant chemotherapy (three FAM, five doxifluridine or 5-FU plus cisplatin, and one doxifluridine plus mitomycin-C). The median disease-free interval of relapsed patients was 33.0 months (range $=16.4-55.6$ months). Twenty-six patients $(57.8 \%)$ had multiple metastases involving two or more organs, with the abdominal lymph nodes and liver being the most common sites of metastases.

\section{Efficacy and survival}

A total of 43 patients were assessable for response (Table 2). Of the two patients not assessable, one was lost to follow-up after the first cycle of treatment, and the other died after the first cycle of unknown cause, although brain metastasis was suspected. Of the 43 assessable patients, 2 achieved CR and 20 achieved PR, giving an overall response rate of $48.9 \%(95 \% \mathrm{CI}=30.3-63.5 \%)$ in the ITT population.

There was no difference in overall response rate between patients who were pretreated and who were not with adjuvant

Table I Patient characteristics $(n=45)$

\begin{tabular}{|c|c|c|}
\hline Characteristic & No. & $\%$ \\
\hline \multicolumn{3}{|l|}{ Age (years) } \\
\hline Median & 57 & \\
\hline Range & $20-73$ & \\
\hline \multicolumn{3}{|l|}{ Sex } \\
\hline Male & 32 & 71.1 \\
\hline Female & 13 & 28.9 \\
\hline \multicolumn{3}{|l|}{ ECOG performance status } \\
\hline 0 & 7 & 15.6 \\
\hline । & 35 & 77.8 \\
\hline 2 & 3 & 6.7 \\
\hline \multicolumn{3}{|l|}{ Extent of disease } \\
\hline Relapsed & 10 & 22.2 \\
\hline Initially metastatic & 33 & 73.3 \\
\hline Initially locally advanced & 2 & 4.4 \\
\hline \multicolumn{3}{|l|}{ Prior adjuvant chemotherapy } \\
\hline Yes & 9 & 20 \\
\hline 5-FU+doxorubicin+mitomycin-C & -3 & \\
\hline 5-FU or doxifluridine+cisplatin & -5 & \\
\hline Doxifluridine+mitomycin-C & -1 & \\
\hline No & 36 & 80 \\
\hline \multicolumn{3}{|l|}{ Metastatic sites } \\
\hline Abdominal lymph node & 33 & 73.3 \\
\hline Liver & 20 & 44.4 \\
\hline Peritoneum & 12 & 26.7 \\
\hline Lung & 7 & 15.6 \\
\hline Cervical lymph node & 7 & 15.6 \\
\hline Ovary & 3 & 6.7 \\
\hline \multicolumn{3}{|l|}{ No. of metastases } \\
\hline I & 19 & 42.2 \\
\hline 2 & 15 & 33.3 \\
\hline$\geqslant 3$ & 11 & 24.5 \\
\hline
\end{tabular}

American Joint Committee on Cancer, 2002.

Table 2 Antitumour activity

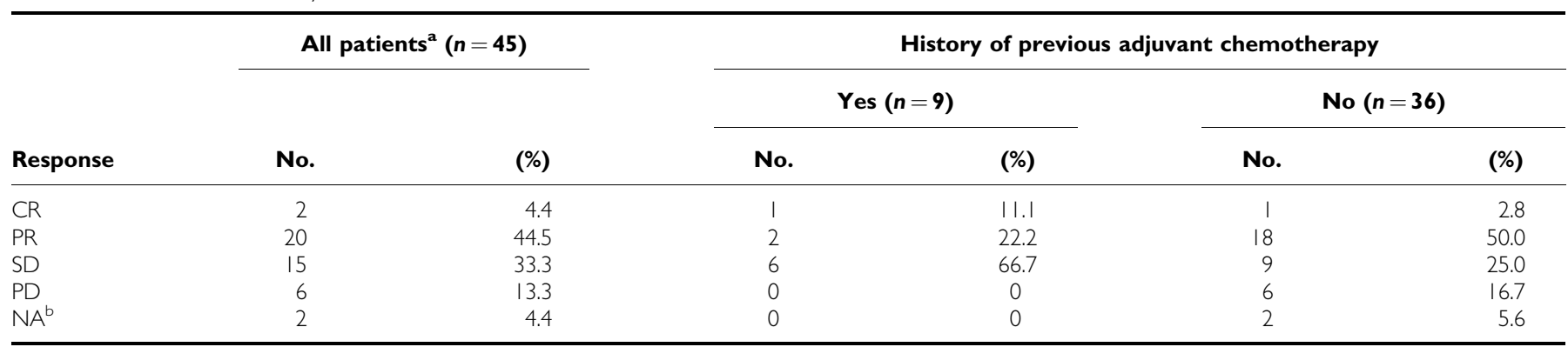

${ }^{\mathrm{a}}$ Intention-to-treat analysis. ${ }^{\mathrm{b}} \mathrm{Not}$ assessable. 
chemotherapy ( 33.3 vs $52.8 \%, P=0.459$ by Fisher's exact test). The median duration of response in the 22 responding patients was 6.1 months (range $=2.9-12.4$ months). The median follow-up period was 42.2 months (range $=31.2-54.3$ months). The median TTP for all patients was 5.6 months $(95 \% \mathrm{CI}=3.9-7.2$ months) (Figure 1), and the median OS was 11.3 months $(95 \% \mathrm{CI}=8.1-14.4$ months) (Figure 2), with a 1-year survival rate of $46.0 \%(95 \% \mathrm{CI}=31.4-$ $60.6 \%)$.

\section{Poststudy treatment}

After disease progression, 28 patients (62.2\%). received secondline chemotherapy, most commonly with irinotecan (21 patients; $75 \%$ ) in combination with cisplatin/mitomycin-C or $5-\mathrm{FU} / \mathrm{LV}$. Two patients $(7.1 \%)$ achieved PR and $5(17.9 \%)$ had stable disease in response to second-line chemotherapy, the median TTP was 1.5 months (95\% CI $=1.3-1.8$ months). Three patients $(6.7 \%)$ received palliative radiotherapy, and one patient underwent total gastrectomy due to cancer bleeding.

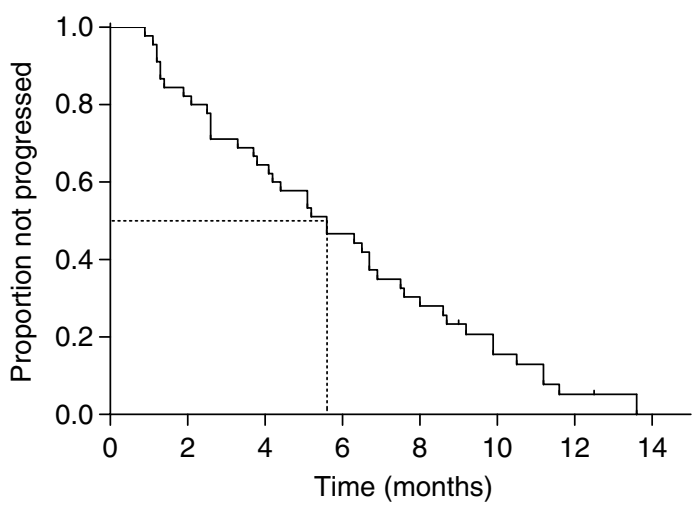

Figure I Time to progression for all patients.

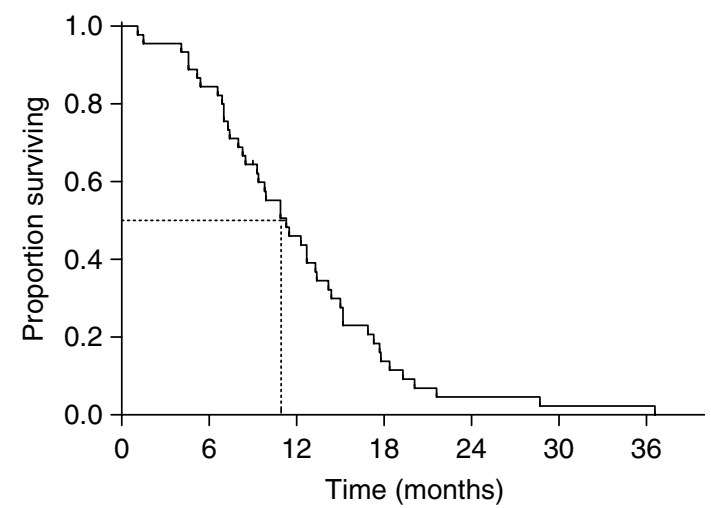

Figure 2 Overall survival for all patients.

\section{Adverse events}

A total of 248 treatment cycles (median $=6$; range $=1-9$ cycles) were administered, with 246 cycles and 43 patients assessable for safety. The frequencies of haematological and non-haematological adverse events are shown in Tables 3 and 4, respectively. The most common haematological adverse event was neutropaenia, which occurred at grade 3 or 4 intensity in 20 patients $(46.5 \%)$ and during 51 cycles $(20.7 \%)$. No patient experienced febrile neutropaenia. There were no treatment-related deaths.

Non-haematological adverse events included asthenia (100\%), alopecia (98\%), neuropathy $(93 \%)$, arthralgia $(86 \%)$, nausea $(74 \%)$, hand-foot syndrome (72\%), myalgia (67\%), and constipation (65\%), but grade 3 or 4 non-haematological adverse events were rare. Treatment was delayed or the dose was reduced during 34 cycles. Treatment was delayed during 5 cycles $(2.0 \%)$ and in 5 patients (11.6\%), due to neutropaenia (2 cycles), elevated transaminase (2 cycles), and hand-foot syndrome (1 cycle). Paclitaxel dose was reduced during 14 cycles $(5.6 \%)$ in 4 patients (9.3\%), due to myalgia (8 cycles), arthralgia (4 cycles), neutropaenia ( 1 cycle) and neuropathy (1 cycle). The dose of capecitabine was reduced during 25 cycles $(10.1 \%)$ in 6 patients $(14 \%)$, due to hand-foot syndrome (17 cycles), and myalgia (8 cycles).

Ten patients $(22.2 \%)$ withdrew from study treatment because of financial problems or paclitaxel-induced neurotoxicity. These 10 patients received a median 3.5 cycles (range $=1-9$ cycles) of capecitabine monotherapy.

Over all treatment cycles, the mean dose intensity of paclitaxel was $57.2 \mathrm{mg} \mathrm{m}^{-2}$ per week (range $=23.3-58.3 \mathrm{mg} \mathrm{m}^{-2}$ per week) and that of capecitabine was $7277 \mathrm{mg} \mathrm{m}^{-2}$ per week (range $=3080-7700 \mathrm{mg} \mathrm{m}^{-2}$ per week), corresponding to 98.0 and $94.5 \%$, respectively of the planned dose intensities. The actual dose intensity of both drugs was maintained at over 95\% during the first 5 chemotherapy cycles (Figure 3). There was $97.5 \%$ compliance with capecitabine treatment during the first 6 cycles.

\section{DISCUSSION}

The results presented here suggest that the combination of paclitaxel and capecitabine is effective and well tolerated as a first-line regimen in patients with AGC. This combination regimen demonstrated promising efficacy, with a tumour response rate of $48.9 \%$, a median TTP of 5.6 months, and a median OS of 11.3 months. These results are comparable to other paclitaxel-based combination regimens in patients with previously untreated AGC. For example, in 29 evaluable patients treated with paclitaxel $175 \mathrm{mg} \mathrm{m}^{-2}$ on day 1 followed by 5 -fluorouracil $1500 \mathrm{mg} \mathrm{m}^{-2}$ on day 2 every 3 weeks, the response rate $65.5 \%$ and the median OS was 12 months (Murad et al, 1999), and the combination of paclitaxel with a 24-h continuous infusion of high-dose 5-FU/ folinic acid and cisplatin in 45 evaluable patients resulted in a $51 \%$ response rate, a median TTP of 9 months, and a median OS of 14 months (Kollmannsberger et al, 2000).

The results of this combination of paclitaxel and capecitabine (TX) seem to be also comparable in efficacy and even better in

Table 3 Haematological toxicity (by patients and cycles)

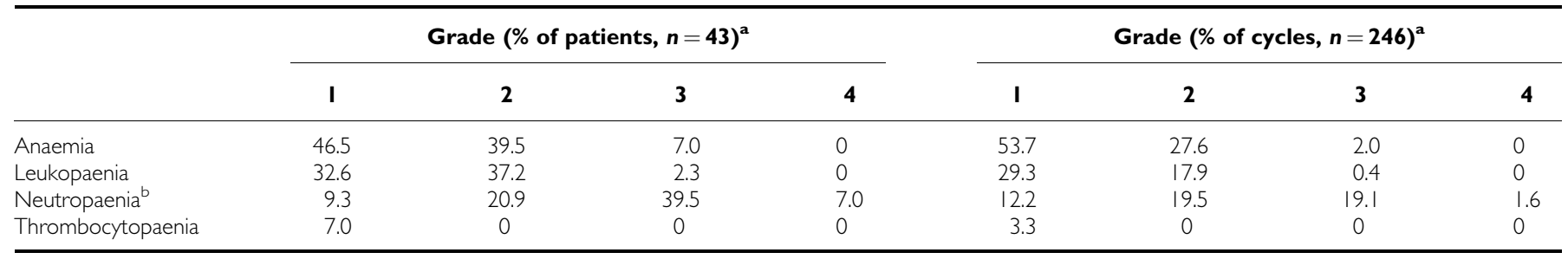

${ }^{a} \mathrm{NCl} \mathrm{CTC}$ version 2.0. ${ }^{b} \mathrm{No}$ febrile neutropaenia or treatment-related death. 
Table 4 Non-haematological toxicity (by patients and cycles)

\begin{tabular}{|c|c|c|c|c|c|c|c|c|}
\hline & \multicolumn{4}{|c|}{ Grade $(\% \text { of patients, } n=43)^{a}$} & \multicolumn{4}{|c|}{ Grade $(\% \text { of cycles, } n=246)^{a}$} \\
\hline & $\mathbf{I}$ & 2 & 3 & 4 & $\mathbf{I}$ & 2 & 3 & 4 \\
\hline Vomiting & 20.9 & 16.3 & 0 & 0 & 8.9 & 3.7 & 0 & 0 \\
\hline Stomatitis & 16.3 & 11.6 & 0 & 0 & 6.9 & 2.4 & 0 & 0 \\
\hline Diarrhoea & 44.2 & 0 & 0 & 0 & 13.8 & 0 & 0 & 0 \\
\hline Constipation & 48.8 & 14.0 & 2.3 & 0 & 20.7 & 3.7 & 0.4 & 0 \\
\hline Neuropathy & 48.8 & 41.9 & 2.3 & 0 & 53.7 & 18.7 & 1.2 & 0 \\
\hline Hand-foot syndrome & 46.5 & 16.3 & 9.3 & 0 & 31.7 & 10.2 & 2.8 & 0 \\
\hline Nail toxicity & 23.3 & 11.6 & 2.3 & 0 & 17.1 & 8.9 & 0.4 & 0 \\
\hline Myalgia & 48.8 & 16.3 & 2.3 & 0 & 32.9 & 7.7 & 0.4 & 0 \\
\hline Arthralgia & 53.5 & 23.3 & 9.3 & 0 & 32.5 & 11.0 & 1.6 & 0 \\
\hline Elevated transaminase & 14.0 & 2.3 & 0 & 0 & 4.9 & 0.8 & 0 & 0 \\
\hline Hyperbilirubinaemia & 14.0 & 4.7 & 0 & 0 & 7.3 & 1.6 & 0 & 0 \\
\hline
\end{tabular}

${ }^{\mathrm{a}} \mathrm{NCl} \mathrm{CTC}$ version 2.0.

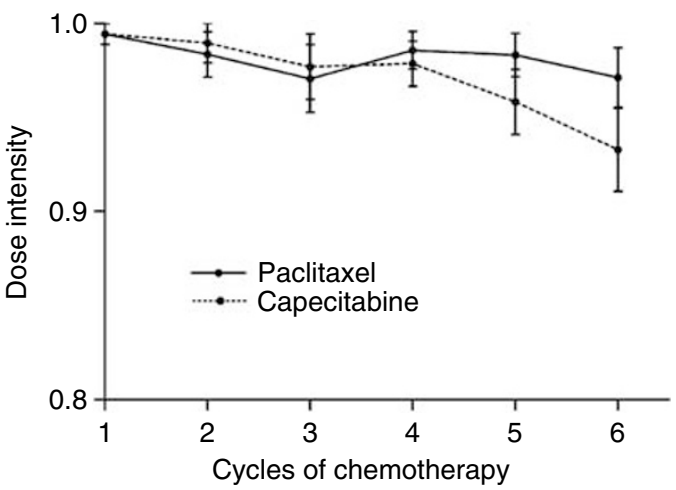

Figure 3 Dose intensity of paclitaxel and capecitabine during cycles I-6.

safety as compared to the current standard platinum-containing first-line regimens. In comparison with capecitabine plus cisplatin (XP) or 5-FU plus cisplatin (FP) combination reported in a recent phase III trial (Kang et al, 2006), this TX regimen was comparable in terms of RR (48.9 vs 46/32\%), TTP (5.6 months vs 5.6/5.0 months), and OS (11.3 months vs 10.5/9.3 months), and even better in terms of risk of severe nausea/vomiting ( $0 v s 6 / 8 \%)$. Similarly, in comparison to ECF of REAL-2 trial (Cunningham et al, 2006), in addition to comparable efficacy, this TX regimen seems to be very safe, especially in terms of infection risk. There was no febrile neutropaenia and treatment-related death with TX regimen, while there was $6.7-9.3 \%$ of febrile neutropaenia with ECF, ECX, EOF, and EOX regimen in REAL-2 trial.

Two trials of paclitaxel/capecitabine combination in patients with metastatic breast cancer (MBC) showed similar toxicities with asthenia, alopecia, and hand-foot syndrome being common (Batista et al, 2004; Gradishar et al, 2004). Although we found that the incidence of grade 3 or 4 hand-foot syndrome and neuropathy were similar in MBC and AGC patients, grade 3 or 4 neutropaenia was lower in MBC (12 and 15\%) than in AGC (46.5\%) patients. This may have resulted from an underestimation in MBC patients due to $\mathrm{CBC}$ evaluations every 3 weeks.
We found that the rate of nail toxicity (all grades) was $37.2 \%$ and the rate of grade 3 hand-foot syndrome was $9.3 \%$. In comparison, the combination of docetaxel $75 \mathrm{mg} \mathrm{m}^{-2}$ i.v. on day 1 and capecitabine $1250 \mathrm{mg} \mathrm{m}^{-2}$ p.o. twice daily on days $1-14$ every 3 weeks resulted in rates of oncolysis (all grades) of $81 \%$ and of grade 3 hand-foot syndrome of 50\% (Park et al, 2004). These differences may have resulted from the lower dose of capecitabine in our regimen and from the use of docetaxel. Although it is difficult to compare the incidence of neutropaenia, we observed no incidence of febrile neutropaenia, whereas the previous trial reported febrile neutropaenia in three patients (7\%). These findings suggest that the combination of paclitaxel and capecitabine may have a superior safety and tolerability profile than the combination of docetaxel and capecitabine.

In previously untreated patients, single-agent docetaxel has demonstrated response rates of 18,20 , and $24 \%$ when given at $100 \mathrm{mg} \mathrm{m}^{-2}$ (Sulkes et al, 1994; Einzig et al, 1996; Mavroudis et al, 2000), and $18 \%$ when given at $75 \mathrm{mg} \mathrm{m}^{-2}$ (Bang et al, 2002). Final results of a randomised phase III trial in chemotherapy-naive patients with locally advanced or metastatic gastric cancer showed that DCF (docetaxel/cisplatin/5-FU) was superior to CF (cisplatin/5-FU) in response rate (37 vs 25\%), TTP (5.6 months vs 3.7 months) and OS (9.2 months vs 8.6 months) (Van Cutsem et al, 2006). However, the haematological toxicity in the DCF arm was significant, with grade 3 or 4 neutropaenia and febrile neutropaenia rates of 82.3 and $30.0 \%$, respectively, suggesting that the DCF regimen has questionable clinical relevance as a standard regimen in patients with AGC.

The lower toxicities, very good compliance and higher dose intensities demonstrated in the present study suggests that dose escalation of capecitabine should be considered in AGC patients. However, a recent retrospective analysis of the impact of dose reduction in $\mathrm{MBC}$ patients treated with capecitabine suggests that the dose of capecitabine can be reduced to minimise toxicity without compromising efficacy (O'Shaughnessy and Blum, 2000).

In summary, we have shown that the combination of paclitaxel and capecitabine is active and highly tolerable as first-line chemotherapy for AGC. Response rates, TTP, and OS compare favourably with previous studies of paclitaxel/5-FU. Replacing infusional 5-FU with oral capecitabine improved convenience and allowed treatment in an outpatient setting.

\section{REFERENCES}

Ajani JA, Fairweather J, Dumas P, Patt YZ, Pazdur R, Mansfield PF (1998) Phase II study of Taxol in patients with advanced gastric carcinoma. Cancer J Sci Am 4: 269-274

Bae JM, Won YJ, Jung KW, Park JG (2002) Annual Report of the Korea Central Cancer Registry Program 2000: based on registered data from 131 hospitals. Cancer Res Treat 34: 77-83 
Bang YJ, Kang WK, Kang YK, Kim HC, Jacques C, Zuber E, Daglish B, Boudraa Y, Kim WS, Heo DS, Kim NK (2002) Docetaxel $75 \mathrm{mg} / \mathrm{m}(2)$ is active and well tolerated in patients with metastatic or recurrent gastric cancer: a phase II trial. Jpn J Clin Oncol 32: 248-254

Batista N, Perez-Manga G, Constenla M, Ruiz A, Carabantes F, Castellanos J, Gonzalez Baron M, Villman K, Soderberg M, Ahlgren J, Casinello J, Regueiro P, Murias A (2004) Phase II study of capecitabine in combination with paclitaxel in patients with anthracycline-pretreated advanced/metastatic breast cancer. Br J Cancer 90: 1740-1746

Blum JL, Jones SE, Buzdar AU, LoRusso PM, Kuter I, Vogel C, Osterwalder B, Burger HU, Brown CS, Griffin T (1999) Multicenter phase II study of capecitabine in paclitaxel-refractory metastatic breast cancer. J Clin Oncol 17: 485-493

Bollag W, Hartmann HR (1980) Tumor inhibitory effects of a new fluorouracil derivative: 5'-deoxy-5-fluorouridine. Eur J Cancer 16: $427-432$

Cao S, Lu K, Ishitsuka H, Rustum YM (1997) Antitumor efficacy of capecitabine against fluorouracil-sensitive and -resistant tumors. Proc Am Soc Clin Oncol 16: (abstract 795)

Cascinu S, Ficarelli R, Safi MA, Graziano F, Catalano G, Cellerino R (1997) A phase I study of paclitaxel and 5-fluorouracil in advanced gastric cancer. Eur J Cancer 33: 1699-1702

Cascinu S, Graziano F, Cardarelli N, Marcellini M, Giordani P, Menichetti ET, Catalano G (1998) Phase II study of paclitaxel in pretreated advanced gastric cancer. Anticancer Drugs 9: 307-310

Cho EK, Lee WK, Im SA, Lee SN, Park SH, Bang SM, Park DK, Park YH, Shin DB, Lee JH (2005) A phase II study of epirubicin, cisplatin and capecitabine combination chemotherapy in patients with metastatic or advanced gastric cancer. Oncology 68: 333-340

Cunningham D, Rao S, Starling N, Iveson T, Nicolson M, Coxon F, Middleton G, Daniel F, Oates J, Norman AR (2006) Randomised multicenter phase III study comparing capecitabine with fluorouracil and oxaliplatin with cisplatin in patients with advanced oesophagogastric (OG) cancer: The REAL 2 Trial. Proc Am Soc Clin Oncol 24: (LBA 4017)

Einzig AI, Neuberg D, Remick SC, Karp DD, O’Dwyer PJ, Stewart JA, Benson III AB (1996) Phase II trial of docetaxel (Taxotere) in patients with adenocarcinoma of the upper gastrointestinal tract previously untreated with cytotoxic chemotherapy: the Eastern Cooperative Oncology Group (ECOG) results of protocol E1293. Med Oncol 13: 87-93

Garcia AA, Leichman CG, Lenz HJ, Baranda J, Lujan R, Casagrande Y, Leichman L (2001) Phase II trial of outpatient schedule of paclitaxel in patients with previously untreated metastatic, measurable adenocarcinoma of the stomach. Jpn J Clin Oncol 31: 275-278

Glimelius B, Ekstrom K, Hoffman K, Graf W, Sjoden PO, Haglund U, Svensson C, Enander LK, Linne T, Sellstrom H, Heuman R (1997) Randomized comparison between chemotherapy plus best supportive care with best supportive care in advanced gastric cancer. Ann Oncol 8: $163-168$

Gradishar WJ, Meza LA, Amin B, Samid D, Hill T, Chen YM, Lower EE, Marcom PK (2004) Capecitabine plus paclitaxel as front-line combination therapy for metastatic breast cancer: a multicenter phase II study. $J$ Clin Oncol 22: 2321-2327

Hartmann HR, Bollag W (1980) 5'-deoxy-5-fluoruridine, a new antineoplastic pyrimidine antimetabolite. Schweiz Med Wochenschr 110: $1078-1080$

Hong YS, Song SY, Lee SI, Chung HC, Choi SH, Noh SH, Park JN, Han JY, Kang JH, Lee KS, Cho JY (2004) A phase II trial of capecitabine in previously untreated patients with advanced and/or metastatic gastric cancer. Ann Oncol 15: $1344-1347$

Ishikawa T, Sekiguchi F, Fukase Y, Sawada N, Ishitsuka H (1998a) Positive correlation between the efficacy of capecitabine and doxifluridine and the ratio of thymidine phosphorylase to dihydropyrimidine dehydrogenase activities in tumors in human cancer xenografts. Cancer Res 58: $685-690$

Ishikawa T, Utoh M, Sawada N, Nishida M, Fukase Y, Sekiguchi F, Ishitsuka H (1998b) Tumor selective delivery of 5-fluorouracil by capecitabine, a new oral fluoropyrimidine carbamate, in human cancer xenografts. Biochem Pharmacol 55: $1091-1097$

Ishitsuka H (2000) Capecitabine: preclinical pharmacology studies. Invest New Drugs 18: $343-354$

Jemal A, Thomas A, Murray T, Thun M (2002) Cancer statistics, 2002. CA Cancer J Clin 52: 23-47

Kang YK, Kang WK, Shin DB, Chen J, Xiong J, Wang J, Lichinitser M, Salas MP, Suarez T, Santamaria J (2006) Randomized phase III trial of capecitabine/cisplatin (XP) vs continuous infusion of 5-FU/cisplatin (FP) as first-line therapy in patients (pts) with advanced gastric cancer (AGC): efficacy and safety results. Proc Am Soc Clin Oncol 24: (LBA4018)

Kang YK, Kim TW, Chang HM, Ryu MH, Yook JH, Oh ST, Kim BS, Lee JS (2004) A phase I/II trial of docetaxel, capecitabine, and cisplatin as a first line chemotherapy for advanced gastric cancer. Proc Am Soc Clin Oncol 22: (abstract 4066)

Kano Y, Akutsu M, Tsunoda S, Ando J, Matsui J, Suzuki K, Ikeda T, Inoue Y, Adachi K (1996) Schedule-dependent interaction between paclitaxel and 5fluorouracil in human carcinoma cell lines in vitro. Br J Cancer 74: 704-710

Kim NK, Park YS, Heo DS, Suh C, Kim SY, Park KC, Kang YK, Shin DB, Kim HT, Kim HJ (1993) A phase III randomized study of 5-fluorouracil and cisplatin $v s$ 5-fluorouracil, doxorubicin, and mitomycin $\mathrm{C} v s$ 5fluorouracil alone in the treatment of advanced gastric cancer. Cancer 71: $3813-3818$

Kim TW, Kang YK, Ahn JH, Chang HM, Yook JH, Oh ST, Kim BS, Lee JS (2002) Phase II study of capecitabine plus cisplatin as first-line chemotherapy in advanced gastric cancer. Ann Oncol 13: 1893-1898

Kollmannsberger C, Quietzsch D, Haag C, Lingenfelser T, Schroeder M, Hartmann JT, Baronius W, Hempel V, Clemens M, Kanz L, Bokemeyer C (2000) A phase II study of paclitaxel, weekly, 24-h continuous infusion 5fluorouracil, folinic acid and cisplatin in patients with advanced gastric cancer. Br J Cancer 83: 458-462

Mavroudis D, Kourousis C, Androulakis N, Kalbakis K, Agelaki S, Kakolyris S, Souglakos J, Sarra E, Vardakis N, Hatzidaki D, Sarmonis G, Georgoulias V (2000) Frontline treatment of advanced gastric cancer with docetaxel and granulocyte colony-stimulating factor (G-CSF): a phase II trial. Am J Clin Oncol 23: $341-344$

Murad AM, Petroianu A, Guimaraes RC, Aragao BC, Cabral LO, ScalabriniNeto AO (1999) Phase II trial of the combination of paclitaxel and 5fluorouracil in the treatment of advanced gastric cancer: a novel, safe, and effective regimen. Am J Clin Oncol 22: 580-586

Murad AM, Santiago FF, Petroianu A, Rocha PR, Rodrigues MA, Rausch M (1993) Modified therapy with 5-fluorouracil, doxorubicin, and methotrexate in advanced gastric cancer. Cancer 72: 37-41

O'Shaughnessy J, Blum J (2000) A retrospective evaluation of the impact of dose reduction in patients treated with xeloda (capecitabine). Proc Am Soc Clin Oncol 19: (abstract 400)

Park YH, Kim BS, Ryoo BY, Yang SH (2006) A phase II study of capecitabine plus 3-weekly oxaliplatin as first-line therapy for patients with advanced gastric cancer. Br J Cancer 94: 959-963

Park YH, Ryoo BY, Choi SJ, Kim HT (2004) A phase II study of capecitabine and docetaxel combination chemotherapy in patients with advanced gastric cancer. Br J Cancer 90: 1329-1333

Pyrhonen S, Kuitunen T, Nyandoto P, Kouri M (1995) Randomised comparison of fluorouracil, epidoxorubicin and methotrexate (FEMTX) plus supportive care with supportive care alone in patients with nonresectable gastric cancer. Br J Cancer 71: 587-591

Rowinsky EK, Cazenave LA, Donehower RC (1990) Taxol: a novel investigational antimicrotubule agent. J Natl Cancer Inst 82: 1247-1259

Sawada N, Ishikawa T, Fukase Y, Nishida M, Yoshikubo T, Ishitsuka H (1998) Induction of thymidine phosphorylase activity and enhancement of capecitabine efficacy by Taxol/Taxotere in human cancer xenografts. Clin Cancer Res 4: 1013-1019

Schipper DL, Wagener DJ (1996) Chemotherapy of gastric cancer. Anticancer Drugs 7: 137-149

Simon R (1987) How large should a phase II trial of a new drug be? Cancer Treat Rep 71: 1079-1085

Sulkes A, Smyth J, Sessa C, Dirix LY, Vermorken JB, Kaye S, Wanders J, Franklin H, LeBail N, Verweij J (1994) Docetaxel (Taxotere) in advanced gastric cancer: results of a phase II clinical trial. EORTC Early Clinical Trials Group. Br J Cancer 70: 380-383

Therasse P, Arbuck SG, Eisenhauer EA, Wanders J, Kaplan RS, Rubinstein L, Verweij J, Van Glabbeke M, van Oosterom AT, Christian MC, Gwyther SG (2000) New guidelines to evaluate the response to treatment in solid tumors. European Organization for Research and Treatment of Cancer, National Cancer Institute of the United States, National Cancer Institute of Canada. J Natl Cancer Inst 92: 205-216

Van Cutsem E, Moiseyenko VM, Tjulandin S, Majlis A, Constenla M, Boni C, Rodrigues A, Fodor M, Chao Y, Voznyi E, Risse ML, Ajani JA, V325 Study Group (2006) Phase III study of docetaxel and cisplatin plus fluorouracil compared with cisplatin and fluorouracil as first-line therapy for advanced gastric cancer: a report of the V325 Study Group. J Clin Oncol 24: 4991 - 4997

Vanhoefer U, Rougier P, Wilke H, Ducreux MP, Lacave AJ, Van Cutsem E, Planker M, Santos JG, Piedbois P, Paillot B, Bodenstein H, Schmoll HJ, 
Bleiberg H, Nordlinger B, Couvreur ML, Baron B, Wils JA (2000) Final results of a randomized phase III trial of sequential high-dose methotrexate, fluorouracil, and doxorubicin $v s$ etoposide, leucovorin, and fluorouracil $v s$ infusional fluorouracil and cisplatin in advanced gastric cancer: A trial of the European Organization for Research and Treatment of Cancer Gastrointestinal Tract Cancer Cooperative Group. J Clin Oncol 18: 2648-2657

Villalona-Calero MA, Blum JL, Jones SE, Diab S, Elledge R, Khoury P, Von Hoff D, Kraynak M, Moczygemba J, Kromelis P, Griffin T, Rowinsky EK (2001) A phase I and pharmacologic study of capecitabine and paclitaxel in breast cancer patients. Ann Oncol 12: 605-614

Webb A, Cunningham D, Scarffe JH, Harper P, Norman A, Joffe JK, Hughes M, Mansi J, Findlay M, Hill A, Oates J, Nicolson M, Hickish T, O’Brien M, Iveson T, Watson M, Underhill C, Wardley A, Meehan M (1997) Randomized trial comparing epirubicin, cisplatin, and fluorouracil $v s$ fluorouracil, doxorubicin, and methotrexate in advanced esophagogastric cancer. J Clin Oncol 15: 261-267

Yamada Y, Shirao K, Ohtsu A, Boku N, Hyodo I, Saitoh H, Miyata Y, Taguchi T (2001) Phase II trial of paclitaxel by three-hour infusion for advanced gastric cancer with short premedication for prophylaxis against paclitaxel-associated hypersensitivity reactions. Ann Oncol 12: $1133-1137$ 